\title{
CHIVO EXPIATORIO, INTERCAMBIO SACRIFICIAL, VIOLENCIA Y CORPORALIDAD
}

\author{
Hilderman Cardona Rodas
}

Facultad de Ciencias Sociales y Humanas; Universidad de Medellín (Colombia)

Resumen Este texto desarrolla una reflexión de la relación entre culto, celebración y sustituto sacrificial en la fundación del tiempo-espacio humano. Para ello, se recurre a la novela de D. H. Lawrence The Plumed Serpent (La Serpiente Emplumada), donde se retrata una corrida de toros. Para leer este fragmento de la novela, el argumento que articula el texto tiene como soporte enunciativo el concepto de chivo expiatorio de René Girard, el de fetiche desarrollado por Auguste Comte y el análisis de Michel Serres sobre el intercambio sacrificial que le da sustrato a toda práctica social humana.

Palabras-clave: chivo expiatorio, sacrificio, violencia, cuerpo.

Bode expiatório, troca sacrificial, violência e corporalidade

Resumo Este artigo desenvolve uma reflexão sobre a relação entre culto, celebração e substituto sacrificial na fundação do tempo-espaço humano. Para isso, o autor recorre ao romance de D. H. Lawrence's, The Plumed Serpent, onde é representada uma tourada. Para ler este fragmento do romance, o argumento que articula o texto tem como suporte expositivo o conceito de bode expiatório de René Girad, o conceito de fetichismo desenvolvido por Auguste Comte, e a análise de Michel Serres sobre a troca sacrificial que sustenta a totalidade da prática social humana.

Palavras-chave: bode expiatório, sacrifício, violência, corpo.

\section{Spacegoat, sacrificial exchange, violence and corporality}

Abstract This article develops a reflection on the relationship among between cult, celebration, and sacrificial substitution in the foundation of human time-space. For this purpose, the author resorts to D. H. Lawrence's novel The Plumed Serpent, where a bullfight is depicted. For reading this fragment of the novel, the argument articulating the text has as an finds expository support in René Girad's concept of the scapegoat, the concept of fetishism developed by Auguste Comte, and Michel Serres' analysis on the of sacrificial exchange which supports the whole totality of human social practice.

Keywords: scapegoat, sacrifice, violence, the body.

Bouc émissaire, substitution sacrificielle, violence et corporalité

Résumé Cet article propose une réflexion sur la relation entre culte, célébration et substitution sacrificielle dans la fondation du temps-espace humain. L'auteur utilise pour cela le roman de D. H. Lawrence, Le Serpent à Plumes, où est décrite une corrida. Pour lire ce passage du roman, l'argument qui structure le texte s'appuie sur le concept de bouc émissaire de René Girad, le concept de fétichisme développé par Auguste Comte et l'analyse de Michel Serres sur la substitution sacrificielle à la base de toute la pratique sociale humaine.

Mots-clés: : bouc émissaire, sacrifice, violence, corps.

Los hombres están expuestos a un contagio violento que desemboca a menudo en ciclos de venganza, de violencias en cadena que son todas semejantes, de manera evidente, porque se imitan unas a otras. Es por esto por lo que digo: el verdadero secreto del conflicto y de la violencia es la imitación deseante, el deseo mimético y las rivalidades. (Girard, 2006: 21) 


\section{Preámbulo: fundación del tiempo-espacio humano ${ }^{1}$}

Una premisa fundamental articula este texto: "el campesino cohabita con su dios pagano en el elemento del paisaje" (Serres, 2002: 315). El espacio pagano, suma de las prácticas locales, se constituye por la combinatoria de piezas del un cuerpo de divinidades rústicas, lugar de la memoria donde el politeísmo o el paganismo despliegan la piel del elemento local antes del nacimiento del verbo. El vestido de Arlequín nos sirve para comprender este plano proyectivo del estar ahí habitando los lugares propios de los seres dotados de vida.

El lenguaje y el monoteísmo vuelven homogéneo el andrajo pagano, la técnica pasa sobre los altares: destrucción de los viejos dioses vecinales, abolición del feudo y de los límites. El empirismo respeta y hace vivir cien divinidades locales, adorará incluso la del verbo. El monoteísmo hace posible la intervención técnica global: para formar un espacio isótropo fue necesario primero matar a los ídolos. (Serres, 2002: 316)

Volviéndose narración en el espacio fenomenológico de la interpretación en la escena de la corrida de toros de la novela de D. H. Lawrence The Plumed Serpent, publicada en 1926 después de un viaje dos años atrás a Ciudad de México junto con su esposa Frieda von Richthofen y la artista Dorothy Brett, ${ }^{2}$ es apreciable el paisaje de la multitud, la muchedumbre, sus sonidos, sus ruidos en el compuesto de fuerzas de un paisaje local: la ciudad de México. Muchedumbre ebria por la voluntad de poder en un sedimento pagano que pone en escena un alma colectiva multiplicada y trasmutada por el vector fetiche de la violencia y lo sagrado: voluntad colectiva de intercambio, voluntad de introducirse en cada rincón, voluntad de poder inscrita en cada singularidad, expresión de cólera, distribuciones de miradas asesinas, intensidades entre la pluma y la escama (el águila y la serpiente) donde es dibujado un espectáculo social, un fractal en la mirada del intercambio sacrificial: "Everybody careful, as far as possible, not to touch anybody else. You don't elbow your neighbour if he's got a pistol on his hip and a

1 Este texto se circunscribe a las líneas de fuerza reflexivas desarrolladas en la tesis doctoral Iconografías Médicas. Dermatología Clínica en Colombia y España durante la Segunda Mitad del Siglo XIX, investigación presentada a la Universitat Rovira i Virgili de Tarragona-España (Cardona Rodas, 2016).

2 La novela The Plumed Serpent (La Serpiente Emplumada) escrita por el novelista inglés D. H. Lawrence (1885-1930), obra de una profunda riqueza antropológica, narra el viaje de una mujer irlandesa de cuarenta años, llamada Kate Leslie, junto con unos americanos a México, quien siente ser un pájaro en torno al cual se enrosca una enorme serpiente. He aquí el símil onírico con la serpiente emplumada conocida en el mundo mesoamericano prehispánico como Quetzalcóalt, símbolo, mito y culto de origen múltiple: unión de agua y tierra expresada en la serpiente-jaguar de la fertilidad; así mismo, este símbolo es personificado por el pájaro-serpiente como una manifestación de lo celeste en tanto deidad. El dios Quetzalcóalt sería el despliegue del vínculo entre hombre, pájaro y serpiente desde una concepción antropocéntrica. La novela de Lawrence se circunscribe en el contexto de la Revolución Mexicana (1910-1920) y noveliza los recuerdos del autor en su peregrinaje desde Nuevo México a Ciudad de México y Oaxaca en 1924 con su esposa Frieda y amigos. 
knife at his belly" (Lawrence, 2000 [1926]). ${ }^{3}$ Lugar donde emerge el grito y la visita del fetiche que circula como mercancía en un cuerpo social que apuesta, intercambia y adora. La muchedumbre celebra, idolatra al "gallardo torero" que se exhibe en la corrida de toros. Lo aclama ante los largos y arqueados cuernos del toro, el cual sale corriendo, a ciegas, como si su euforia primera se ejerciera en la oscuridad, desconcertado después, ante los movimientos frenéticos en la plaza. Víctima del recambio, víctima sacrificial. La sustitución sacrificial tiene por objeto engañar la violencia, dice René Girard (1995), ${ }^{4}$ en un adulterio largo en el que yo me convierto en otro y el otro se convierte en mí: el vestido negro de la bestia, la forma de sus cuernos y de la muleta, la actitud noble en los riñones del torero y la cabeza taurina elevada. Todo se decide allí por la parada relacional de domesticación recíproca. "El animal nos hace reconocer que el saber nace con la apariencia del cuerpo, músculo, forma, gestos y movimiento; la parada la prepara. O: no hay nada en el conocimiento que no se prepare alli'" (Serres, 2001: 61). Encanto de concomitancias confesionales. Lawrence describe este acontecimiento de operación sacrificial:

A toreador came forward and switched out a pink cloak like a fan not far from the bull's nose. The bull gave a playful little prance, neat and pretty, and charged mildly on the cloak. The toreador switched the cloak over the animal's head, and the neat little bull trotted on round the ring, looking for a way to get out.

The bull trotted waveringly and somewhat irritated. The toreadors waved their cloaks at him, and he swerved on. Till his vague course took him to where one of the horsemen with lances sat motionless on his horse.

The bull trotted suspiciously up to the motionless horse bearing the rider with the long pole; a lean old horse that would never move till Doomsday, unless someone shoved it.

3 " $[. .$.$] todo el mundo cuidadoso, dentro de lo posible, de no tocar a nadie. Uno no propina un$ codazo al vecino si éste lleva un pistola al cinto y un cuchillo sobre el vientre" (Lawrence, 2000 [1926]: 12). Aquí se sigue la traducción revisada de la novela por Pilar Giralt para la editorial española Montesinos en 2000. La versión en inglés puede consultarse en el Project Gutenberg Australia (http://gutenberg.net.au/ebooks03/0300021h.html).

4 René Girard, crítico literario, historiador y filósofo francés (1923-2015), fundamento su reflexión en una reacción contra el racionalismo que ignora la naturaleza de la ilusión religiosa y su papel fundador de toda sociedad. Por ello, en todo grupo social existe una cohesión inconsciente fundamentada en una violencia inconfesable manifiesta en los mitos y las formas de lo sagrado. La violencia constituiría una presencia ausente que se vuelve operativa al ser negada y naturalizada. En la base se encuentra una crítica a la teoría freudiana sobre la castración y el complejo de Edipo, pues, según Girard, no se alcanza a comprender desde esta perspectiva cómo la rivalidad funda al objeto del deseo. La envidia y los celos le dan sustrato a las relaciones entre las personas (máscaras miméticas), cuando cada quien desea lo otro, desear lo que no se tiene, es para adsorberlo y destruirlo. Aquí, el sacrificio del chivo expiatorio funciona como phármakon (remedio y veneno) para permitir el funcionamiento de lo social. En esta antropología del deseo un libro como la Biblia sería una expresión de sociología fantástica donde se despliega el deseo mimético del intercambio sacrificial del chivo expiatorio que fundamenta un tiempo-espacio monoteísta. En la revista Ciencias Sociales y Educación, No. 8, de la Facultad de Ciencias Sociales y Humanas de la Universidad de Medellín se le publicó un homenaje al pensador francés a partir de una serie de traducciones del francés al español de artículos a propósito de su obra, el cual puede consultarse en: https://revistas.udem.edu.co/index.php/Ciencias_Sociales/issue/view/146 
The picador pulled his feeble horse round slowly, to face the bull, and slowly he leaned forward and shoved his lance-point into the bull's shoulder. The bull, as if the horse were a great wasp that had stung him deep, suddenly lowered his head in a jerk of surprise and lifted his horns straight up into the horse's abdomen. And without more ado, over went horse and rider, like a tottering monument upset.

The rider scrambled from under the horse and went running away with his lance. The old horse, in complete dazed amazement, struggled to rise, as if overcome with dumb incomprehension. And the bull, with a red place on his shoulder welling a trickle of dark blood, stood looking around in equally hopeless amazement. (Lawrence, (2000 [1926]) ${ }^{5}$

Pero la herida le dolía. Vio la extraña forma del caballo tratando de levantarse del suelo, y olió a sangre e intestinos. Por eso, vagamente, sin saber muy bien lo que debía hacer, el toro levantó una vez más la cabeza y clavó sus agudos y vigorosos cuernos en el vientre del caballo, moviendo allí dentro de arriba abajo con una especie de vaga satisfacción. ${ }^{6}$

Este movimiento de paisaje local recuerda el compuesto de fuerzas que se dan en las empresas de construcción de duraciones: religión, ideología o arte. Reflexionemos en la figura simbólica del toro y el caballo. El toro adquiere la función de fetiche por su virilidad; después de sus genitales lo que lo domina es su espalda. En ella reside su fuerza. "De ahí parte la cornada y el esfuerzo del trabajo bajo el yugo. En cambio, tiene una grupa flaca y sin iniciativa. Cuando el toro se da la vuelta, son sus miembros posteriores los que se desplazan y giran alrededor de sus miembros anteriores" (Tournier, 2000: 41). La hembra del toro tiene una función en la mitología humana en tanto nodriza natural, animal madre por excelencia. Vaca = madre + naturaleza. Así las dos operaciones sacrificiales: toro que muere en la

5 “Un torero se adelantó e hizo ondear una capa rosa, como un abanico, ante el hocico del toro. Éste dio un salto juguetón, limpio y bonito, y embistió suavemente la capa. El torero la pasó por encima de la cabeza del animal, y el pequeño toro dio una vuelta al ruedo, buscando la salida. [...] El toro trotó un poco, vacilante y algo irritado. Los toreros le hacían señas con sus capas, y él embestía. Hasta que su vacilante curso le llevó al lugar donde uno de los jinetes con picas se encontraba inmóvil sobre el caballo. [...] El toro trotó, desconfiado, hasta el caballo inmóvil montado por el hombre que jamás caminaría hasta el juicio final si alguien le empujara. [...] El picador hizo dar media vuelta a su débil montura para enfrentarse al toro, y lentamente se inclinó hacia delante y clavó la punta de la pica en el hombro del toro. Éste, como el caballo fuese un gran avispa que le hubiera picado con fuerza, bajó de pronto la cabeza en un gesto de sorpresa y levantó los cuernos dentro del abdomen del caballo. Y sin más, caballo y jinete rodaron por el suelo como un movimiento derivado. [...] El jinete salió de debajo de caballo y se alejó corriendo con su pica. El viejo caballo, totalmente aturdido, trató de ponerse en pie, como vencido por una muda incomprensión. Y el toro, con una mancha roja en el hombro, que rezumaba un hilo de sangre oscura, se quedó mirando a su alrededor con un asombro igualmente mudo." (Lawrence, 2000 [1926]: 15)

6 El grupo de indie rock Alt-J posee un videoclip llamado Something Good (2012), claramente ilustrativo sobre la situación plasmada por Lawrence. El espectáculo sacrificial adquiere colores en comunión orgásmica entre el torero, el toro y el público en términos de una escena corporal de posibles ante un sacrificio de mutuas implicaciones fundadoras: sacrificio, muerte, vida, tiempo, miedo, circo y sentimiento encarado ante la dynamis que integra naturaleza y cultura pliegan sus fuerzas enunciativas y simbólicas en la constitución del tiempo-espacio humano. Puede verse en el videoclip en el siguiente enlace: https://www.youtube.com/watch?v=aNYjOVo5IEw 
corrida como un sacrificio ritual y vaca que muere en el matadero como venganza de un crimen contranatura. El caballo se asienta enteramente en su grupa; sus nalgas enormes y su larga crin le hacen adquirir la función fetiche de la feminidad. “Todo en él parte de la grupa, la coz, como un muelle, y el esfuerzo de tracción. Hay que añadir el estiércol, pues el caballo es el único mamífero que ha sabido exaltar la defecación. También es el único que posee nalgas, y eso lo acerca al hombre más que cualquier otro animal" (Tournier, 2000: 42). El caballo, al girar sobre si mismo, lo hace exhibiendo su grupa y son sus miembros anteriores los que se deslizan. Corre, huye y se desplaza a gran velocidad.

La experiencia del viaje expresada en La Serpiente Emplumada de Lawrence pone en juego ese paisaje local en el tiempo de las duraciones: sacrificio, violencia, religión, muerte y erotismo. Entre 1923 y 1925, Lawrence realizó tres viajes a México llegando a permanecer en ese país durante unos once meses. Estuvo en Ciudad de México y en la costa occidental desde Sonora hasta Oaxaca buscando el espacio pagano donde el simbolismo de lo sagrado se despliega en el cuerpo de las divinidades rusticas que no han sido parasitadas por la racionalidad genocida occidental ligada a la obsesión de progreso y parasitismo tecnológico. Lawrence se alimenta del escepticismo propio de su época ligado a la "decadencia de Occidente" y al pensamiento utilitarista y tecnocrático donde "el sueño de la razón produce monstruos", como lo recuerda Francisco de Goya en su aguafuerte publicado en 1799.

América era entonces, para Lawrence, esa ilusión, de raigambre spengleriana, que alimentaría también las fantasías de una vida nueva, más íntegra y más humana en muchos otros escritores europeos. [...] Lo que el viajero inglés buscaba en tierras americanas era fundar una comunidad de hombres libres, desasidos de la racionalidad mecanicista que infestaba Europa, capaces de vivir plenamente todas las instancias intelectuales, afectivas y libidinales que la estrecha moral occidental imposibilitaba (y cuyos inquisidores, en Inglaterra, habían prohibido la publicación de su novela [The Rainbow]). Eso solo sería posible en América, ese Nuevo Continente que todavía no imponía barreras férreas a la libre manifestación del espíritu, donde el hombre podría realizar en plenitud su voluntad interior. (Pereira, 2013: 66).

Su viaje a México, además del sur de los Estados Unidos, corresponde a un anhelo de hallar un paraíso terrenal y una tierra redentora. Un periplo por los tejidos oníricos de la condición corporal humana para reconocerse en la mirada del otro y habitar la experiencia de lo diverso en el alma de las cosas que palpita en la vida como obra de arte.

El viaje imposible es ese viaje que ya nunca haremos más. Ese viaje que habría podido hacernos descubrir nuevos paisajes y nuevos hombres, que habría podido abrirnos el espacio de nuevos encuentros. Eso ocurrió alguna vez y algunos europeos sin duda experimentaron entonces fugitivamente lo que nosotros experimentaríamos hoy si una señal indiscutible nos probara la existencia, en alguna parte del espacio, de seres vivos capaces de comunicarse con nosotros. (Augé, 1998: 15-16) 
Por ello, en Lawrence el viaje constituye un potencial cósmico para reencontrar el vínculo del hombre con la naturaleza y su vitalidad en las fuerzas de la vida en el ritual del sacrifico. Así,

La serpiente emplumada es un acto de autognosis, desde fuera, con la mirada puesta en otra cultura desgarrada por sus contradicciones y en busca de una respuesta a la crisis occidental de Europa. Lawrence se sumerge en las aguas profundas de la historia de México para encontrar las antiguas fuerzas de la naturaleza. (Bernal, 2008: 64)

\section{Resonancias del intercambio sacrificial en el phármakon (veneno-remedio)}

En el pasaje de Lawrence, se escucha al espectador y el espectáculo al alzarse las banderillas e inmolarse la espada ante la arremetida de los cuerpos. Golpe de espa$\mathrm{da}$, golpe de cuernos y mirada fascinada de los otros, desorbitados, en un remolino de carne, furor, olor a muerte y sacrificio, fundación. El torero, el toro y el caballo se encarnan en un despliegue de fuerzas que reverberan en la estocada, la embestida y el espanto.

El campaneo resonaba, he aquí la hora de la estocada. Frente a la bestia, espada plana y encorvada apuntando al codillo, cuerno libre ante la ingle frente al hombre, todos dos, hocico bajo, entrañas ofrecidas, frente a la corta eternidad de la angustia limitada: ellos se abalanzan el uno hacia el otro, quien embiste recibe la embestida. Instante suspendido, solemne y resolutivo, donde no se sabe si la espada o el cuerno penetran profundamente en la ingle o la espada, nupcias roja y negra en su ápex, inmovilidad estatuaria. (Serres, 1989: 44)

Esta es la faena de los fetiches, una escena de la historia de las religiones: placa tectónica de avance lento cuyos efectos provoca convulsiones estructurantes en superficies. En medio del bullicio y del torbellino, dos cuerpos, en adulterio largo por domesticación recíproca, se funda en una sola estatua inmediata, un grafo en la red posible de relaciones: "Este es el instante simétrico donde las dos sombras caen la una hacia la otra, cuando la espada del matador se levanta por encima de la muleta y que la bestia alza bruscamente la cabeza solemnidad inmemorial, matrimonio, mezcla, alianza de dos razas" (Serres, 1989: 45), instante proyectado de la relación-inscripción del nacimiento de lo divino.

¿Quién muere en este ritual? Es una incertidumbre que se juega. Pero se sabe quién va a morir: el toro, puesto que él celebra la sustitución sacrificial en el momento del paso o la suplencia de las víctimas. En lo virtual de la muerte, en esa incertidumbre que se juega, se da el instante simétrico, geometral, en el espacio o frontera de la lógica y del verbo, circunstancia en que emerge la historia y el tiempo puesto que el hombre se libera de la muerte, nace haciendo pasar, filtrándose, percolándose, por medio de la violencia ejercida sobre otro viviente. Es así como la estatua, en el grito múltiple del 
primer hombre, es polimorfa, pagana, politeísta, con cabeza humana y con grupa de bestia (esfinge o centauro); se inmoviliza y representa el paso del sacrificio humano al sacrificio animal, en donde la bestia es inmolada como hombre: hacer un Mismo con Otro en el espacio local de doble juego, esfuerzo de fundación y esfuerzo de desvelamiento. Estatuas de la sustitución. "Nosotros participamos entonces en los sacrificios antes de asistir a la misa, paganos antes del cristianismo." (Serres, 1989: 46)

El rito social del sacrificio modela un juego mimético en la figura pagana de la fundación en un eterno retorno de un paganismo reactualizado y ritualizado. ${ }^{7}$ Por ello, la espiral de la violencia, de la venganza y de la sangre es intensificada por la ritualidad desplegada por el poder, el cual tiene al otro como escenario sacrificial en los mecanismos de la supervivencia fundamentada en la muerte.

La violencia es, en efecto, la primera experiencia religiosa. El trauma, el miedo y a la vez fascinación, que, para la gente de los tiempos prehistóricos, debió suponer la capacidad creadora de la naturaleza y la violencia letal de los animales carnívoros hizo que quedaran personificadas en deidades o elevadas a realidades suprahumanas. La primera reacción ante la violencia es su externalización. La cultura arcaica no conoce esa "violencia de la naturaleza", su causa de naturaleza interna se conoce perfectamente y de ahí que no inspire miedo. La violencia en el interior de la sociedad, en consecuencia, se entiende como resultado de una violencia que irrumpe en la sociedad desde afuera. Ni siquiera la enfermedad y la muerte son un acontecimiento operado en el interior del cuerpo. Más bien, remiten a una violencia externa. Toda muerte es violenta. No existe la muerte "natural" ni la "violencia de la naturaleza" (Han, 2016:26)

Miedo, trauma y fascinación constituyen la violencia como una externalización en el tiempo-espacio humano, en el interior de la sociedad, el emerger como impulso fundador, y en el interior del cuerpo, donde se ejerce la corporeidad simbólica de lo social. Es pertinente retomar aquí la categoría de immunitas que trabaja Roberto Esposito (2009). Según Esposito, una comunidad se vale de ciertas estrategias inmunitarias para evitar el peligro del contagio de lo común o contagio de la relación, donde la presencia del cuerpo anormal supone un miedo a ser contagiado. Por ello, la comunidad se distancia de ese cuerpo manteniéndolo próximo para ser vigilado y agenciado a partir de un dispositivo biopolítico en el que confluyen saber, poder y subjetividad en el control de las corporalidades asimiladas como peligrosas: "al

$7 \quad$ En un bello homenaje que leyó Michel Serres en sesión pública de la Academia Francesa el 15 de diciembre de 2005, el filósofo francés exalta la obra de René Girard para comprender las acciones sacrifíciales que fundan el tiempo-espacio humanos. "El origen de la tragedia que buscó Nietzsche, sin encontrarla, usted la ha descubierto; yace, toda ofrecida, en la raíz helénica del término mismo: $\tau \rho \alpha \gamma o \sigma$ significa, en efecto, el "chivo", ese chivo expiatorio que las masas prestas a la carnicería expulsan cargándolo con los pecados del mundo, los suyos propios, y cuya imagen invierte el Cordero de Dios. Gracias por haber arrojado la luz en la caja negra que ocultamos entre nosotros." (Serres, 2015: 277). René Girard apoyaría a Michel Serres en 1984 en su vinculación como profesor de historia de las ciencias en la Universidad de Stanford, donde compartieron espacios de reflexión académica y amistad. 
peligro cada vez más difundido que amenaza a lo común responde la defensa cada vez más compacta de lo inmune" (Esposito, 2009: 13). Se pretende inmunizar al cuerpo social de los vectores de contagio que constituyen veneno pero también remedio para la salud biopolítica de la población. Así, enfermedad, cuerpo, poder, saber y biopolítica confluyen en un procedimiento inmunitario de inclusión excluyente o de exclusión mediante una inclusión que materializa al phármakon como figura social del mal o veneno-remedio que representa una corporalidad peligrosa expresada en las superficies patológicas.

Al poner al cuerpo en el centro de la política y a la posibilidad de la enfermedad en el centro del cuerpo, la biopolítica hace de esta por una parte el margen externo del que la vida debe distanciarse continuamente; por otra, el pliegue interno que la reconduce dialécticamente a sí misma. La figura clave de este pasaje es aquella, clásica, del phármakon, entendido desde el origen de la tradición filosófica en el doble sentido de medicina y de veneno; pero aquí interpretado más específicamente como antídoto necesario para defender la vida de la posibilidad disolutiva de su "puesta en común" (Esposito, 2009: 27).

Aquí la puesta en obra de un dispositivo biopolítico en relación con el phármakon, a partir de una lógica inmunitaria, tendrá que ver con una medicalización de los cuerpos anómalos y enfermos que son incluidos-excluidos en la función vicaria del chivo expiatorio (Girard, 1995, 2002), que es un mismo en tanto otro y otro en tanto un mismo al cual no es posible apresarlo por ninguna identidad. "Mal y antídoto, veneno y cura, poción y contra-poción, el phármakon no es una sustancia, sino más bien una no-sustancia, una no-identidad, una no-esencia" (Esposito, 2009: 181), que expone a la vida, la enfermedad, la muerte y al cuerpo en una farmacia social, médica y jurídica inmunitaria.

La figura del chivo expiatorio pone en todo su paroxismo biopolítico la imagen del cuerpo desecho (Cardona Rodas, 2017) en una racionalidad tanatopolítica que fusiona moral y dogmatismo. Este cuerpo expone el horror puritano a contaminarse con la sangre que emana del chivo expiatorio.

Los antiguos griegos lo llamaron phármakos; los judíos, chivo expiatorio, los cristianos, Agnus Dei y los soldados de las Cruzadas, cabeza de turco. Una máscara cambiante, religiosa o ideológica, se ha ido adaptando a cada época y lugar para disimular la necesidad vicaria de proyectar las frustraciones colectivas en un tercero. Sin una vía de escape que periódicamente catalice los odios entre unos y otros la raza humana seguramente acabaría autoexterminándose. (Adell, 2011: 7)

La fundación del tiempo-espacio humano precisa del ritual de la muerte del chivo expiatorio para diseminar el miedo en el espacio pagano. La muerte de la víctima, animal u hombre, inaugura el lugar de la memoria en la práctica humana del sacrificio (Girard, 1995; Cardona Rodas, 2013). Los cuerpos supliciados, torturados o que exhiben las huellas de la muerte y que son captados y representados por imágenes en su diversidad de tiempo y lugar, patrimonios visuales de la barbarie y del 
espectáculo del horror, muestran la necesidad de un tercero sacrificado que sacia la euforia de la masa, expía sus culpas y apacigua el miedo heredado de la muerte al ser cristalizada en el cuerpo de otro. He aquí el vínculo entre muerte, erotismo, violencia y sacrificio (Bataille, 2005), como se aprecia en una postal fotográfica de principios del siglo $X X^{8}$ que deja ver el cuerpo supliciado de un hombre a quien se le aplica el sacrificio chino de los cien cortes o Leng Tche, el cual consistía en practicar un suplicio público de desmembramiento paulatino a un siervo, a quien se la había dado opio previamente, que hubiera matado a su amo o cometido un delito de lesa majestad.

La muerte por los cien cortes constituía una tortura y ejecución de una persona viva en una especie de ritual sagrado y político de suplicio ligado a la depuración de la vida por la muerte. Por ello, Leng Tche tiene que ver con ascender lentamente a una montaña. En este sentido, Georges Bataille (2005) sostiene que:

La víctima muere, y entonces los asistentes participan de un elemento que esa muerte les revela. Este elemento podemos llamarlo, con los historiadores de las religiones, lo sagrado. Lo sagrado es justamente la continuidad del ser revelada a quienes prestan atención, en un rito solemne, a la muerte de un ser discontinuo. Hay, como consecuencia de la muerte violenta, una ruptura de la discontinuidad de un ser; lo que subsiste y que, en el silencio que cae, experimentan los espíritus ansiosos, es la continuidad del ser, a la cual se devuelve la víctima. Solo una muerte espectacular, operada en las condiciones determinadas por la gravedad y la colectividad de la religión, es susceptible de revelar lo que habitualmente se escapa a nuestra atención. [...] Todo nos lleva a creer que, esencialmente, lo sagrado de los sacrificios primitivos es análogo a lo divino de las religiones actuales. (Bataille, 2005: 87-88)

Las huellas encarnadas de la violencia ponen de manifiesto lo sagrado y lo profano en el acto sacrificial del chivo expiatorio. En ese acto sacrificial puede apreciarse el grado de satisfacción, erótica, en el exterminio del enemigo, donde el antagonismo entre el bien y el mal hace del acto violento y macabro la justificación del asesinato, según la lógica del chivo expiatorio y el acto sacrificial que funda lo social (Girard, $1995,2006)$. Un componente sagrado subyace en la violencia sobre los cuerpos, pues cuando la masa se encuentra en crisis busca la figura del chivo expiatorio, el cual se asimila como culpable de la crisis y, por ello, responsable de la perdición de la comunidad, pero que, al ser eliminado, al sacrificarlo, la crisis se supera, con lo que se restablece el orden perturbado. Así, la doble función de la víctima (culpable/salvador) produce lo sagrado. Por ello, en el asesinato no se trata de un hecho individual, sino social, en un contexto religioso legitimado por la consigna del cordero de Dios que quita el pecado del mundo, para otorgar la paz. Una limpieza social de todo elemento visto como peligroso, enfermo y anormal (Cardona Rodas, 2012).

8 El suplicio chino de los cien cortes o Leng Tche era una técnica de ejecución práctica en China desde el 900 d.C. hasta su supresión en 1905. La postal fotográfica que se refiere puede consultarse en: http://2.bp.blogspot.com/_ftMfK8LtODw/SC0W9i8M6SI/AAAAAAAAAFc/KAW61wujHn0 /s1600/3.jpg 
En esta lógica del sacrificial se pone de manifiesto una dialéctica negativa (Adorno, 2005) fundamentada en un antagonismo fundacional en la personificación del bien y el mal, de la civilización y de la barbarie, base de una justificación social del odio que proyecta lo cultural. En la historia de Colombia este teatro de la crueldad, como caso para entender lo aquí expuesto, lo constituye el asesinato del caudillo liberal Jorge Eliecer Gaitán en 1948. En tal acontecimiento la figura del héroe-mártir (Gaitán) y del enemigo-asesino (Roa) le sustrato a una proyección religiosa y política de la venganza en una estética macabra naturalizada de la muerte, lo cual tiene toda su potencia en la sociedad colombiana actual. ${ }^{9}$ Roa, cabeza de turco, está presente en la serie de fotografías de Sady Gonzalez sobre el asesinato de Gaitan, donde el espectáculo de la muerte atrae por su dimensión cinestésica que involucra la mirada, el tacto y el olor en una escena macrabra. En una de las fotos de Sady González un grupo de personas se han dispuesto alrededor del cuerpo lapidado de Roa en el Cementerio Central de Bogotá. El cadáver se encuentra inclinado, desnudo, en un ataud improvisado y con algunas prendas de vestir que cubren parte de su cuerpo, este habia permanecido en las escalas del Palacio Presidencial durante dos días depositado allí por la muchedumbre que lo había linchado. Resalta el gesto de algunas personas que con un pañuelo en mano no soportan el olor putrefacto que emana del cuerpo de Roa. Cada uno posa para la toma fotográfica en un espectáculo de atracción morbosa del cuerpo vicario que ha sido sacrificado por la turba enardecida que por amor a la venganza inmoló a Roa como phármakon.

Violencia, barbarie y crueldad aplicadas sobre y en los cuerpos, están presentes en el patrimonio visual, fílmico y literario en Colombia, desde la década de los cincuenta del siglo XX hasta hoy. Al analizar este patrimonio la banalización del mal (Arendt, 2003) y la naturalización de la crueldad y del odio demandan explicaciones sociales en tanto los elementos puestos en juego en su ejecución, no son factores de orden patológico (o psicológico) en lo individual, sino características que son un resultado de condiciones específicas y que, en otro caso, tienen una significación que

9 "La historia parece que mereciera o escogiera a sus protagonistas. Esa elección no está determinada por cualidades, sino que más bien parece la selección arbitraria de inusitados y juguetones duendes. A ella se ha llegado por la gloria, a esta primera categoría pertenecen, por ejemplo, Alejandro Magno, conquistador en plena juventud de casi todo el territorio conocido; Colón, empobrecido si se quiere al final de sus días, pero finalmente reconocido de manera universal; Napoleón, conquistando territorios y deponiendo monarquías a lo largo de Europa a nombre de los ideales de la Revolución Francesa para aspirar a ser más rey que los reyes; Bolívar o San Martín en América, indiscutidos como libertarios a pesar de conocidas dificultades. Pero a la historia también se puede acceder por la infamia, y esta es una segunda categoría. Hitler, referencia obligada de la descalificación de todos los tiranos del siglo XX, es su arquetipo. Aún la literatura rescata esta categoría cuando, por ejemplo, Jorge Luis Borges escribe su Historia universal de la infamia. Una tercera categoría de aspirantes a la historia por reconocidas obras o hechos pasan por periodos de olvido o son arrojados de ella; Sandro Botticelli permaneció con sus obras escondidas en los depósitos de las galerías de arte italianas sin lograr ver la luz por más de un centenar de años. Existe además una cuarta categoría de personajes, merecedores por sus hechos a aspirar a la historia pero excluidos sistemáticamente de ella. No se les reconoce gloria, infamia ni olvido, no son dignos ni siquiera del repudio, simplemente parecen no haber existido, son precisamente los escindidos de ella. Juan Roa Sierra, en nuestro caso, corre exactamente ese riesgo." (Ramírez, 2008: 195-196). 
sólo pueden ser social. En este sentido es pertinente recoger la pregunta que se hacía la etnóloga francesa Nohoum-Grappe: ¿por qué y bajo qué condiciones la crueldad se convierte en un modo dominante de comunicación en un espacio social dado? (Blair, 2004: 180).

Este tipo de puestas en escena es apreciable en las fotografías producidas a raíz de la muerte del narcotraficante Pablo Escobar en la ciudad de Medellín en 1993. En ellas el acontecimiento de la muerte ofrece un espectáculo fanático del linchamiento del mal, donde quienes son retratados exhiben con placer la crueldad y el absurdo de una sociedad que ha legitimado el odio y naturalizado el crimen.

\section{Auguste Comte y el furor del fetiche}

La relación entre sacrificio, sustitución y violencia es posible encontrarla en Auguste Comte en su Cours de Philosophie Positive publicado entre 1830 y 1842 en París. El "estado teológico" de las culturas planteado por él opera como sustrato que sedimenta toda práctica social humana en la necesidad de producirnos. Necesidad que queda satisfecha "por nuestra tendencia inicial a transportar a todo tipo de humano, asimilando toda clase de fenómenos a los que nosotros mismos producimos, y que, como tales, comienzan por parecernos bastante conocidos, según la intención inmediata que los acompaña" (Comte, 1980 [1830-1842]: 106) He aquí el ejemplo de la escena taurina.

Tres formas acompañan el estado teológico. La primera la constituye el fetichismo, definida como la voluntad de atribuir a los cuerpos exteriores una vida análoga a la humana pero más enérgica, el furor del fetiche está en su relación con las fuerzas sacrificiales, o, como dice Comte, por su "acción generalmente más poderosa". Sin embargo, Comte pone en juego cierto psicologismo criticable, cuando afirma que "la adoración de los astros caracteriza el grado más elevado de esta primera fase teológica que, al principio, definen apenas el estado mental en el que se quedan los animales superiores" (Comte, 1980 [1830-1842]: 106). Si son el instinto y el pensamiento los que prevalecen en esta fase, el geometral de relaciones y de posibles se positiviza por el ejercicio sacrificial, fetichista. Una segunda forma está dada por el politeísmo. Aquí el espíritu teológico representa la libre preponderancia especulativa.

La filosofía inicial experimenta aquí la más profunda transformación que puede registrarse en el conjunto de su destino real, en el sentido de que al fin se retira la vida a los objetos materiales, para ser misteriosamente trasladada a diversos seres ficticios, habitualmente invisibles, cuya activa y continua intervención pasa a ser fuente directa de todos los fenómenos exteriores, e incluso luego los fenómenos humanos. (Comte, 1980 [1830-1842]: 106-107)

Para Comte esta fase es la más ascendiente, mental y social del espíritu teológico, y es donde se encuentra la mayor parte de nuestra especia humana. La tercera forma la constituye el monoteísmo donde comienza la inevitable declinación de la filosofía 
inicial con la inserción de la razón, el verbo, que va restringiendo el dominio anterior de la imaginación y desarrollándose el sentimiento universal de la sujeción necesaria de todos los fenómenos naturales a leyes invariables. De esta manera Auguste Comte sostiene que

[...] esa filosofía inicial ha sido tan necesaria a los primeros pasos de nuestra sociabilidad como a los de nuestra inteligencia, bien para establecer primitivamente nuestras doctrinas comunes, sin las cuales el vínculo social no hubiera podido adquirir ni extensión ni consistencia, bien suscitando espontáneamente la única autoridad espiritual que entonces pudiera surgir. (Comte, 1980 [1830-1842]: 109)

Tres instancias que se actualizan en la integral diferencial del sacrificio. Tanto politeísmo como monoteísmo consiste en función del fetichismo, en donde lo vivo rechaza la muerte para partir del reino de la inercia, contrario universal de la vida universal, y por medio del límite ineluctable. Culto, celebración y sustituto sacrificial se instalan en la fundación de un tiempo humano de un sueño despierto contemplativo y ficcional. ${ }^{10}$

Para Comte es esencial integrar la historia de las religiones con la historia de las ciencias, haciendo de la naturaleza humana y de la historia del hombre homogéneas entre sí. Recurriendo a Michel Serres, es posible afirmar que la historia de las relaciones de lo uno con lo múltiple en los niveles y estratos posibles de formalización hace parte de cualquier práctica humana. Traspaso de señales e imágenes que pueden ser analizadas como mito, como leyenda, como tragedia, como fábula o como historia; todo un circuito empujado por signos y sentidos presentados como huellas escrituras o geometral del mito a la historia y hasta de la historia al mito. La historia se pliega en múltiples facetas, múltiples movimientos, múltiples análisis, se bifurca en mito y en razón, en fábula y novela. La historia se noveliza, se estructura a partir de los elementos narrativos de orden algebraico, combinatorio, provisto de muchas operaciones, muchas relaciones con características definidas u ocultas en las huellas y en los gritos, en la caja negra. Es así como para Georges Dumezil (1984) la historia es una multiplicidad, una totalidad efectuante, plegada y puesta en funcionamiento en órdenes económicos o escriturarios, "digamos que es la totalidad concebida en el tiempo, de lo que un grupo, un grupo de grupos humanos o, en último extremo, el género humano cree saber de los acontecimientos de un pasado material y moral, desde los primeros esbozos hasta los balances más recientes" (Dumezil, 1984: 59)

Un "religión de la Humanidad", en los términos de Comte, significa la alianza del hombre consigo y con los otros, un verdadero equivalente general y universal concreto. ${ }^{11}$ Una religión que liga el adentro con el afuera, lo sagrado-soporte con los signos, la concepción de la expresión y la idea con la forma. Un fetichismo que funciona como sustrato material que asegura las luchas de las veneraciones, las mezclas, las mercancías y los intercambios. Garantiza cierta relación de orden.

10 Cfr. Georges Canguilhem (1998) y François Dagognet (1997).

11 Dos textos de Michel Serres sirven para comprender esta asociación monádica: El Contrato Natural (1991) y Hominiscencia (2001). 
La relación de orden produce los valores - dice Serres - , desencadena las guerras, en el gran fetiche. En la matriz de los fetiches. Ella designa los envites, fija los precios. Es lo que queda del reino animal. Es la huella, en nuestros grupos, de las bestias que fuimos. Ella es prehominiana. Lobos, perros, corderos, bandas, jaurías, rebaños. El hombre nace del abandonarlas. Nacerá. (Serres, 1983: 67)

Ante la relación de orden, ante la alianza de la violencia con lo sagrado, en donde las cosas ya no son cosas en mercancías. El Gran Ser vive a través de la celebración del cuerpo social: los ritos presentifican y vivifican esta existencia.

Así, se puede concluir este texto con un pasaje de D. H. Lawrence, en el que se despliega el orden de lo sagrado en un complejo de fuerzas profanas:

Gods should be iridescent, like the rainbow in the storm. Man creates a God in his own image, and the gods grow old along with the men that made them. But storms sway in heaven, and the god-stuff sways high and angry over our heads. Gods die with men who have conceived them. But the god-stuff roars eternally, like the sea, with too vast a sound to be heard. Like the sea in storm, that beats against the rocks of living, stiffened men, slowly to destroy them. Or like the sea of the glimmering, ethereal plasm of the world, that bathes the feet and the knees of men as earth-sap bathes the roots of trees. Ye must be born again. Even the gods must be born again. We must be born again. (Lawrence, 2000 [1926]) $)^{12}$

\section{Conclusiones}

La teoría mimética de René Girard permite vislumbrar el poder simbólico de la violencia en la fundación del tiempo-espacio humano que tiene como operador sacrificial la figura del chivo expiatorio. En este horizonte comprensivo, los mitos y la religión permiten encontrarse con los cimientos de la cultura que tienen su proyección en la política. Este texto trazo una relación entre culto, celebración y sustituto sacrificial teniendo como soporte la novela de Lawrence The Plumed Serpent en el apartado sobre una corrida de toros, la noción de chivo expiatorio, el problema del fetiche en Auguste Comte y los planteamientos de Michel Serres sobre el intercambio sacrificial, sin dejar de recurrir a otra serie de argumentaciones para mostrar cómo las huellas encarnadas de la violencia tienen como escenario sacrificial al cuerpo (reflejo de lo Otro en lo Mismo en un

12 “Los dioses deberían ser iridiscentes, como el arco iris en la tormenta. El hombre crea a un Dios a su propia imagen, y los dioses envejecen junto a los hombres que los crearon. Pero las tormentas claman en el cielo, y la noción de Dios está siempre alta y airada sobre nuestras cabezas. Los dioses mueren con los hombres que los han concebido, pero la noción de Dios permanece eternamente, surgiendo como el mar, cuyo sonido es demasiado basto para ser captado. Rugiendo como el mar embravecido, que se estrella contra las rocas de hombres vivos y rígidos, a fin de destruirlos. O como el mar del centellante y etéreo plasma del mundo, que baña los pies y las rodillas de los hombres como la savia de la tierra baña las raíces de los árboles. Hemos de nacer otra vez. Incluso los dioses han de nacer otra vez. Todos hemos de nacer otra vez" (Lawrence, 2000 [1926]: 58). 
eterno retorno de la violencia y en una dialéctica negativa) en la fuerza enérgica de lo cultural y en el uso del intercambio simbólico de la muerte.

El asunto de la violencia y el intercambio sacrificial pone en escena al cuerpo como locus en la fundación del tiempo-espacio humano. Como lo plantea Søren Kierkegaard en Frygt og Bæven (1843 [2014], Temor y Temblor), lo que para un creyente es un sacrifico propiaciatorio, para un ateo es la fiel muestra de un cruel asesinato; desde una óptica laica es un acto egoísta, para la devota es muestra de renuncia suprema. Así, la figura del chivo expiatorio proyecta un ritual macabro y en un juego entre sacrificio, expiación, poder, exhibición y simbolismo erótico de la muerte. Es pues aquí donde la antropología de la violencia encuentra su campo de acción tratando de establecer un análisis sobre las características de la barbarie y la crueldad, que permite encontrar las explicaciones y las significaciones de un acto violento y macabro en la sociedad. Los actos violentos justificados en una supuesta justicia es la otra parte que se puede encontrar en el tema de violencia. La justificación del maltrato o el asesinato por el deseo de venganza o de una creíble justicia que motiva a la sociedad a cumplir el ojo por ojo diente por diente, donde el cuerpo del otro cumple la función de chivo expiatorio y lugar sacrificial para fundación del tiempo-espacio humano. La violencia, y en su máxima expresión la masacre, son actos de barbarie y crueldad que encuentran su incentivo de realización en la venganza, la justicia, el fanatismo religioso, el racismo, aplicados para justificar conductas marcada por el despliegue de odio y la maldad.

\section{Bibliografía}

Adell, Anna (2011), El Arte como Expiación, Madrid, Casimiro.

Adorno, Theodor (2005), Dialéctica Negativa. La Jerga de la Autenticidad, Madrid, Akal.

Alt-J (2012), Something Good, álbum debut de estudio An Awesome de los compositores Joe Newman, Gus Unger-Hamilton, Gwilym Sainsbury y Thom Green.

Arendt, Hannah (2003), Eichmann en Jerusalén. Un Estudio acerca de la Banalidad del Mal, Barcelona, Lumen.

Augé, Marc (1998), El Viaje Imposible, Barcelona, Gedisa.

Bataille, Georges (2005), El Erotismo, Barcelona, Tusquets.

Bernal Alanís, Tomás (2008), “La serpiente emplumada: una mirada a las aguas profundas de México", Fuentes Humanísticas, 20 (36), pp. 59-67, disponible en: http://fuenteshumanisticas.azc.uam.mx/index.php/rfh/article/view/288/277 (última consulta en septiembre 2019).

Blair, Elsa (2004), “Mucha sangre y poco sentido: o un análisis antropológico de la violencia", Boletín de Antropología, 35, Medellín, Universidad de Antioquia.

Canguilhem, Georges (1998, 11 de julio), "Historia de las religiones e historia de las ciencias en la teoría del fetichismo en la obra de Augusto Comte", Sociología, Unaula, 11.

Cardona Rodas, Hilderman (2012), Experiencias Desnudas del Orden. Cuerpos Deformes y Monstruosos, Medellín, Universidad de Medellín. 
Cardona Rodas, Hilderman (2013), "Podredumbres: el parásito como átomo de relación en filosofía, literatura y medicina", Cuadernos de Pesquisa Interdisciplinar en Ciencias Humanas, 104, Florianópolis, Universidad Federal de Santa Catarina, disponible en: https://periodicos.ufsc.br/index.php/cadernosdepesquisa/article/view/1984-8951.201 3v14n104p85/25210 (última consulta en septiembre 2019).

Cardona Rodas, Hilderman (2016), Iconografías Médicas. Dermatología Clínica en Colombia y España durante la Segunda Mitad del siglo XIX, Tarragona, Universitat Rovira i Virgili, tesis doctoral.

Cardona Rodas, Hilderman (2017), “Testimonios visuales de la violencia: el cuerpo desecho", en Hilderman Cardona Rodas y Juan Luis Ramírez Torres (comps.), Narrativas Corporales y Estéticas del Dolor, México, DF, y Medellín, Universidad de Medellín y Universidad Autónoma del Estado de México.

Comte, Auguste (1980 [1830-1842]), Curso de Filosofía Positiva (Lecciones 1 y 2). Discurso sobre el Espíritu Positivo, Barcelona, Orbis.

Dagognet, François (1997, junio), “Sobre cierta unidad del pensamiento de Augusto Comte: ¿ciencia y religión inseparables?", Sociología, Unaula, 20.

Dumezil, Georges (1984), "Del mito a la historia”, en VV.AA., Historia y Diversidad de las Culturas, Barcelona, Ediciones del Serbal, UNESCO, pp. 59-69.

Esposito, Roberto (2009), Immunitas. Protección y Negación de la Vida, Buenos Aires, Amorrortu.

Girard, René (1995), La Violencia y lo Sagrado, Barcelona, Anagrama.

Girard, René (2002), El Chivo Expiatorio, Barcelona, Anagrama.

Girard, René (2006), Aquel por el Que Llega el Escándalo, Madrid, Caparrós Editores.

Han, Byung-Chul (2016), Topología de la Violencia, Barcelona, Herder Editorial.

Kierkegaard, Søren (2014 [1843]), Temor y Temblor, Madrid, Alianza Editorial.

Lawrence, David Herbert (2000 [1926]), La Serpiente Emplumada, Barcelona, Montesinos, traducción de Pilar Giralt, versión en inglés de The Plumed Serpent disponible en el Project Gutenberg Australia: http://gutenberg.net.au/ebooks03/0300021h.html (última consulta en septiembre 2019).

Pereira, Armando (2013), “D. H. Lawrence: México, la utopía imposible”, Literatura Mexicana, XXIV (1), pp. 65-90, disponible en:

http://www.scielo.org.mx/pdf/lm/v24n1/v24n1a4.pdf (última consulta en septiembre 2019).

Ramírez Elizalde, Laura Astrid (2008), “Juan Roa Sierra: persistencia de un fantasma o la evanescencia del mito", Maguaré, 22, pp. 169-201, Bogotá, Universidad Nacional de Colombia, disponible en:

https://revistas.unal.edu.co/index.php/maguare/article/view/15290/16084 (última consulta en septiembre 2019).

Serres, Michel (1983). Desapego. Apólogo, París, Flammarion, traducción de Luis Alfonso Palau, Medellín, 1999.

Serres, Michel (1989), Estatuas. El Segundo Libro de las Fundaciones, París, Flammarion. Traducción de Marías Cecilia Gómez, Medellín, 1999.

Serres, Michel (1991), El Contrato Natural, Valencia, Pre-Textos.

Serres, Michel (2001), Hominiscencia, Saint-Amand Montrond (Cher), Le Pommier, traducción de Jorge Márquez Valderrama, Medellín, 2002-2003. 
Serres, Michel (2002), Los Cinco Sentidos. Filosofía de los Cuerpos Mezclados, México, Taurus.

Serres, Michel (2015), "Lo trágico y la lástima: discurso de respuesta a René Girard", Ciencias Sociales y Educación, 4 (8), pp. 277-293.

Tournier, Michel (2000), El Espejo de las Ideas. Tratado, Barcelona, El Acantilado.

VV.AA. (2015), “A propósito de René Girard (1923-2015)”, Ciencias Sociales y Educación, 4 (8), pp. 205-293.

Hilderman Cardona Rodas. Profesor de tiempo completo e investigador de la Facultad de Ciencias Sociales y Humanas de la Universidad de Medellín (Colombia), donde es el editor de la revista Ciencias Sociales y Educación. E-mail: hcardona@udem.edu.co

Receção: 12 de junho de 2018 Aprovação: 20 de dezembro de 2018 